\title{
Nurses' experience of caring for palliative-stage patients in a hospital setting in Sweden
}

\author{
Sandra Pennbrant ,' Marzena Tomaszewska, Gabriella Lorentzson Penttilä \\ Department of Nursing, Health and Culture, University West, Sweden
}

Received: December 15, 2014

Accepted: February 2, 2015

Online Published: February 6, 2015

DOI: $10.5430 /$ cns.v3n2p97

URL: http://dx.doi.org/10.5430/cns.v3n2p97

\begin{abstract}
Objective: The aim of this study was to describe nurses' experiences of caring for palliative-stage patients in a hospital setting.

Methods: A qualitative study based on six interviews with strategically selected nurses in an oncology department in western Sweden. The interviews were analyzed using a phenomenological-hermeneutic approach.

Results: The results identified three themes: 1) Developing professional self-confidence; 2) Developing communication skills; and 3) Having time for reflection. Each theme has at least two subthemes.

Conclusions: Caring for palliative-stage patients requires a combination of knowledge, experience and professional and personal self-confidence. Nurses need regular coaching by staff and professionals with more experience dealing with and processing suffering, death and related existential issues. Nurses need to separate work from private life and have satisfying and relaxing leisure activities.
\end{abstract}

Key Words: Nurses experiences, Palliative care, Phenomenological-hermeneutic analysis, Qualitative studies

\section{Introduction}

Nurses working with patients in a palliative phase encounter death, sorrow and emotional situations in their everyday work. Working in a situation constantly requiring ethically charged decisions can be experienced as stressful and lonely. Palliative care strives to achieve the best possible quality of life for patients and relatives. ${ }^{[1]}$ Nurses can experience feelings of insecurity and loneliness when trying to decide how to handle patients and relatives. ${ }^{[2]}$ An overview study on end-of-life caring research shows that many studies focus on the patient's situation, ${ }^{[3-8]}$ only a handful of studies highlight the nurse's situation. This study aims to describe the caring experiences of palliative care nurses in a hospital oncology ward.

\subsection{Research on nurses' experiences of caring for patients in the palliative setting}

Research shows that nurses can suffer from all the emotional impressions received during the provision of palliative care. Caring for dying patients requires a great deal of personal commitment and nurses experience a constant feeling of not doing enough for the patient. ${ }^{[2]}$ It is an issue of wanting to care for the entire patient and not only deal with the diagnosis. ${ }^{[9]}$ When resources are insufficient and nurses are driven by sincere concern for both patient and relatives they may experience feelings of anxiety. ${ }^{[10]}$ Moreover, developing a personal relationship with a cancer patient carries the risk of becoming emotionally overwhelmed and may result in unresolved grief, which may reduce the nurse's subsequent

\footnotetext{
*Correspondence: Sandra Pennbrant; Email: sandra.pennbrant@hv.se; Address: Department of Nursing, Health and Culture, University West,
} Trollhättan, Sweden. 
work ability. ${ }^{[11]}$

Nurses experience frustration and a sense of powerlessness as a result of time shortage, lacking resources and insufficient professional planning. ${ }^{[2,12,13]}$ Clinical care and nurse work satisfaction in the context of palliative care could be improved on the basis of better knowledge about the common psychosocial challenges experienced by end-of-life patients. ${ }^{[14]}$ Insufficient support from physicians and poor communication with them can also lead to stress among palliative care nurses. Communication failure is a source of stress for all parties involved. ${ }^{[2,15]}$

Nurses feel responsible for both patients and their relatives. ${ }^{[2]}$ The ambition of nurses is to provide high-quality care to both the end-of-life patient and to his or her relatives. ${ }^{[16]}$ Palliative care can lead to feelings of exhaustion for nurses, as a result both of their feelings of compassion for the dying patient and the relatives and of the need to discuss difficult ethical issues with them. ${ }^{[17]}$ The greatest challenge when caring for cancer patients is how one should communicate about death. ${ }^{[18]}$ Nurses avoid the issue of death and handle the patient's anxiety in this respect by distancing themselves from the issue, by changing the subject when it emerges in the talks, ${ }^{[19]}$ and by limiting their discourse to medical information only. Emotionally loaded communication does take place, but with little genuine interest. ${ }^{[20]}$ It is important to maintain a good relationship with the patient and nurses speak of the importance of being a good communicator and daring to be present in the patient's suffering. [21]

\subsection{To maintain a good quality of life and reduce suffering in palliative care}

The core task of an oncology nurse is to help the patient live as normal a life as possible, with the best quality of life and the least suffering possible. ${ }^{[22,23]}$ By being attentive to the patient's suffering, and by confirming his or her physical, psychosocial and spiritual life sphere, the nurse can, as part of the palliative care, provide hope, comfort and acknowledgement to both patient and relatives. ${ }^{[24,25]}$ It is therefore crucial that nurses are aware of the common psychosocial concerns experienced by patients and how this awareness can improve both the palliative clinical care provided and the nurses' own work satisfaction. ${ }^{[14]}$

In Eriksson's view, ${ }^{[24,25]}$ the concept of suffering comprises three parts. The first part concerns the patient's suffering due to the disease and general state of illness. The second part concerns the patient's suffering linked to the care received or not received. The third and last part concerns the patient's suffering due to various changes, caused by the state of illness and the related care received, in his or her everyday life. In order for the nurse to be able to deal with the suffering person appropriately, the nurse must be aware of what suffering is and entails. The suffering patient must be able to discuss the suffering with the nurse. Only in this way can something positive be derived from the suffering. The nurse acknowledges the suffering patient by being available as an ordinary fellow human being. To enter into the role as nurse for the suffering patient requires courage. To alleviate the suffering the nurse must make the patient feel respected and acknowledged. It is therefore important the nurse adjust the information provided about illness and treatment to the patient's ability and situation, so that the patient feels he or she is receiving complete information. ${ }^{[26]}$ The nurse can alleviate the patient's suffering by offering discussion and attention, and by providing comfort, encouragement and hope. The nurse must see the suffering as part of a greater whole encompassing the patient's entire life situation. ${ }^{[24,25]}$

Past research describes the situation of patients in advanced palliative units, advanced palliative home care and in hospices. $^{[3-8,27-31]}$ However, there are no specific descriptions of how nurses experience working with palliative care patients in an oncology ward in a Swedish hospital. This study can contribute to increased understanding of the working situation and needs of nurses working in palliative care.

\subsection{Aim}

The aim was to describe how nurses experience working with patients in palliative care in an oncology ward.

\section{Methods}

The study was empirical with a phenomenological-hermeneutic approach and methodology developed by Lindseth and Norberg. ${ }^{[32]}$

Phenomenology was established by Husserl who saw human beings as conscious beings capable of perceiving other conscious beings. Phenomenology deals with attempting to understand and describe experiences of a given phenomenon. Experiences and interpretations of the phenomenon form the basis for how the individual perceives and acts in relation to the surrounding world. A core concept within phenomenology is that of "life world". It can be described as the reality we live in; the reality in which we find ourselves. The goal is to try to explore and understand the world in which humans live. ${ }^{[32]}$

Hermeneutics is the theory of interpretation aiming to create understanding and meaning about phenomena. Core concepts within hermeneutics are preunderstanding, meaning, sense and interpretation. The phenomenological-hermeneutic method has also been inspired by Ricoeur. According to Ricoeur, ${ }^{[33]}$ preunderstanding of life is created by the sorting of experiences to answer the questions "what", "why", "who", "how", "with whom" and "for whom". By means of narration human beings can convey their feelings and experiences. The experience of the phenomenon is always per- 
sonal and can be conveyed to others in the form of a narrative. By interpreting narratives, one can clarify the meaning and convey it between people, in order to gain understanding of the phenomenon and the narrating person's life world

By letting the nurses talk about their experiences in the context of caring for palliative-stage patients, the researchers were able to gain deeper understanding of the phenomenon and the nurses' experiences.

According to Ricoeur, ${ }^{[33]}$ a text contains an inner structure containing more meanings than the researcher's intentions. In the first phase, the inner structure can be clarified by structural analysis. In the second phase, meanings are interpreted by hermeneutic interpretation. The structural analysis is a stage between naive reading and critical interpretation.

\subsection{Selection criteria and respondents}

Strategic selection, meaning the researchers selected the people considered appropriate for the study's aim, was used for the study. ${ }^{[34]}$ In this study, strategic selection in practice meant the researchers automatically selected the first available and appropriate nurses for study inclusion. The advantage of this selection is that the researchers can select the people suitable in relation to the research questions. The inclusion criterion was that the nurses had to work in a palliative oncology ward in somatic hospital care.

To establish contact with nurses in a palliative oncology ward, an informational letter was first sent to the responsible hospital director of a major university hospital in western Sweden, requesting permission to contact the staff and carry out the interview study. Upon receipt of the director's approval, an informational letter was sent to the ward director.

One of the researchers visited the ward at two occasions to ask the nurses present whether or not they would like to participate. At the first visit, four nurses were asked, and three agreed to participate in the study. At the second visit, four other nurses were asked, and three more agreed to participate in the study. The six nurses who agreed to participate were given written information about the study's aim and execution. All the nurses were informed that participation was voluntary and that all data would be treated confidentially.

The study is based on six interviews with nurses working in a palliative oncology ward in somatic hospital care. The ward in question provides care to patients with various forms of cancer from the entire south-western region of Sweden. The ward's patients may be receiving either treatment for complications or palliative care. The treatments received mainly concern cytostatic and radiation therapies. The nurses interviewed worked with both kinds of patients and treatments.

Published by Sciedu Press
The study includes three nurses with several years of work experience with patients in a palliative stage and three nurses who recently started to work with palliative-stage patients in an oncology ward. The nurses were aged from 28 to 43 and all were women. The nurses' work experience as nurses ranged from a couple of months to 17 years. Two nurses had worked for over five years in the oncology ward, two for over a year, and two had recently started to work in the ward. Two nurses had specialist oncology training and four nurses were newly graduated nurses.

In Sweden, the basic nursing program is a three-year program, corresponding to 180 higher education credits (HEC). As part of this program, the nursing students must pass a specialized 7.5 HEC course in palliative care. Specialist oncology training encompasses an additional $60 \mathrm{HEC}$ of courses, including palliative care. Palliative care nurses may adhere to the Swedish Council for Palliative Care, which offers additional palliative care certification when a nurse has completed 10 to 15 HEC of palliative care coursework, in addition to the basic nursing program; however, this was not a selection criterion for this study.

\subsection{Data collection}

Data collection was carried out by two researchers (MT, GLP). Six nurses in the oncology care ward at a hospital in western Sweden were interviewed individually in the spring of 2011. The interviews took place in an undisturbed meeting room at the nurses' place of work, so as to ensure the interview was calm and relaxed. Care was taken to ensure complete privacy and confidentiality. After obtaining the nurse's permission to tape the interview, she once again received both written and oral information about the interview's voluntary nature. The interviews were taped and lasted for 30 to 45 minutes. Subsequently, the interviews were transcribed verbatim.

According to Lindseth and Norberg, ${ }^{[32]}$ a narrative interview is the best method for catching the respondent's life experiences. With the help of narrative texts, the researcher is able to gain insight and understanding into the respondents' experiences and life world. During the interview an interview guide was used. A first open-ended question was put to the respondents: "Can you tell me about your experiences in relation to the care of palliative-stage patients?". To increase the researcher's understanding of the respondent's narrative, follow-up questions were asked, for instance: "Could you explain what you mean by that?".

\subsection{Analysis}

The analysis was carried out according to phenomenological-hermeneutic methodology and the text was processed through the following three phases: naive reading, thematic structural analysis, and interpretation of the whole. ${ }^{[32]}$ 
Naive reading means the researcher reads the text naively several times in order to obtain a first understanding of it as a whole. In this phase the researcher must lay his preunderstanding aside. ${ }^{[32]}$ The researchers read the text individually several times to obtain a view of the whole and an idea of the data's meaning. The naive preunderstanding was continuously compared with the thematic structural analysis. As the naive preunderstanding could not be complete before the thematic structural analysis was complete, one can say that the naive preunderstanding and the thematic structural analysis were created at the same time.

Thematic structural analysis, the second phase of the analysis process, is a methodological example of interpretation of the text by means of division of the text into meaning units, i.e. words, sentences, several sentences, or sections relevant to the study's aim. ${ }^{[32]}$ The meaning units were read jointly by the researchers several times to consider their content. The phenomenological part of the method was used when selecting the meaning units. Meaning units were found in all of the six interviews. Subsequently, the meaning units were condensed to shorten the text and make it easier to handle, while maintaining the essential content. After the reading, similarities and differences in the condensed text were identified in order to develop subthemes and themes. Once the condensing was complete the interpretation process started. When developing the themes and subthemes the researchers used their preunderstanding of the phenomenon. This process resulted in the emergence of new meanings and deeper understanding of the text. The condensed text units were regrouped into subthemes several times, depending on the changes made to the preunderstanding and the comparison of the preunderstanding with the naive reading of the text. Three themes with related subthemes were developed and are the final result of the thematic structural analysis.

During the third and last phase of the interpretation process, the interpreted whole, the text was once again seen as a whole in relation to the study's aim, the naive understanding, the result of the structural analysis, and the researchers' thoughts and preunderstandings, to form a new whole. In this phase, subjective openness was adopted and the new whole combined with the researchers' preunderstanding entailed the emergence of new, previously hidden impressions from the text. This brought about a new whole and deeper understanding. ${ }^{[32]}$

During the interviews, the authors asked follow-up questions and, when necessary, guided the interviewees back to the issue. To reduce bias, the researchers were mindful of the risk that their participation may influence the content of the interview. During the interview analysis process, all the authors (MT, GLP and SP) first read and analyzed each interview on their own, then repeated the process together, carefully identifying and considering alternative interpretations. To strengthen the study's reliability, the data collection method, the analysis process, and the practical execu- tion have been described. ${ }^{[32,34]}$

\subsection{Ethical considerations}

The study complied with the relevant ethical recommendations of the Swedish Research Council. ${ }^{[35]}$ The following four ethical requirements were taken into account: purpose, information, informed consent, confidentiality. Both written and oral information about the study, its aims and use, and the nurses' right to cease participation at their leisure, was provided. In particular, it was explained how the study could contribute to better understanding of nurses' experiences of caring for palliative-stage patients. Prior oral and written consent was obtained from the responding nurses before launching the study. A coding system was used to anonymize the responding nurses' names and workplaces.

\section{Results}

\subsection{Naive reading}

The naive preunderstanding, or the first understanding of the text as a whole, indicated that it is important for nurses to be able to talk with patients and relatives, about the patient's condition and symptoms and about death and existential anguish. The interviewed nurses stated that they experience a feeling of acknowledgment as a result of positive response from patients and relatives. The work in a palliative care ward is psychologically trying and the nurses need coaching and professional skills to handle their own feelings.

\subsection{Thematic structural analysis}

Based on the naive reading, a thematic structural analysis was performed. The analysis generated three themes and their subthemes, which are presented below in the order used in Table 1.

\subsection{Strengthening professional self-confidence}

Strengthening professional self-confidence means being safe in one's professional role, being acknowledged by patients and relatives, cooperating with colleagues and other professional groups, and separating work and private life. In order to feel safe in one's professional role, the interviewed nurses believed it is necessary to constantly search for new knowledge, in particular knowledge pertaining to medical science, caring science and the use of technical equipment. The acknowledgment that nurses receive from the patient and/or relative takes the form of expressions of gratitude, positive responses, and emotional closeness. To coordinate the caring provided to patient and relatives, the nurses underlined the need for establishing good cooperation between colleagues and other professional groups. Professional selfconfidence includes separating work and private life. 


\subsubsection{Being confident in the professional role}

The nurses stated that nurses must be confident in their professional role in order to be able to have a professional demeanor in the meeting with the patient. This requires applying a holistic perspective on the care provided to the patient. The nurses described the need of using oneself and one's experiences when providing care to palliative-stage patients, and when dealing with unexpected events. The more meet- ings nurses have had with end-of-life patients, the safer they experience both their role as nurses and the palliative care provided.

"I now feel much safer in my role as a nurse ... I now feel comfortable. It takes a while to develop, it really does. It isn't something one can do in a week." (R6)

Table 1: Description of themes and subthemes

\begin{tabular}{ll}
\hline Themes & Subthemes \\
\hline Strengthening professional self-confidence & Being confident in the professional role \\
& Being acknowledged by patients and relatives \\
Cooperating with colleagues and other professional groups & Separating work and private life \\
Developing communication skills & Talking with the patient \\
& Talking with the relatives \\
Having time for reflection & Talking about one's feelings \\
& Coaching \\
\hline
\end{tabular}

The nurses with limited experience of palliative care experienced difficulties when trying to have a professional demeanor towards patients and relatives. The difficulty could consist in separating one's own feelings from those of the patient, to not enter too far into the patient's and his or her family situation. The nurses stressed the importance of being available to relatives, of providing them with support in the difficult situation. With the help of the nurse, relatives can handle the situation in the best possible way.

"I must be present and provide support so the patient and the relatives can handle the situation. To be there. I'm not there to take care of their family and death. That's their business. It's like a birth, but in the other direction. I'm supposed to be there, and help them with their anxiety and fear." (R1)

The nurses believed that being insightful and having experience contribute to understanding and accepting that complete symptom alleviation is not always possible. This is something one must accept. Nurses with little experience of the provision of palliative care experienced anxiety and insecurity in their professional role. These feelings concerned the dosages given to the patient, in particular for the purpose of pain relief.

"When one is completely new, one doesn't really know what to give, one doesn't know the doses. When looking back I realize this wasn't good. Sometimes I gave all the things available, which wasn't right. It hurts when there is a death and one feels one failed to alleviate the pain." (R1)

The nurses felt that working in palliative care is instructive and offers new knowledge and experiences daily. Knowledge identified by the nurses in particular included the handling of technical equipment, placing peripheral venous catheters (PVC) and central venous catheters (CVC), and medical knowledge. The nurses considered it important to continuously search for new knowledge, in order to develop their professional role and to have a professional demeanor when meeting palliative-stage patients and relatives.

"I think one learns a lot of things all the time. I learn something every day and it's very exciting and there are always new problems that have to be solved ... to find out why something happened and sort it out." (R3)

The nurses believed that daring to be present in the meeting with the patient entails the nurse using, and developing, her knowledge and experiences in the meeting with the palliative-stage patient. Daring to be present in the care of end-of-life patients also requires a certain degree of emotional maturity. The nurses believed that professional experience improves their emotional maturity. They also felt they need skills in various domains in order to have a holistic perspective on the patient's situation.

"But you can always develop yourself, you can always do things better, there is always something to do. It's so enormously gratifying. You use yourself all the time, although 
maybe not so much at first, because then one is so focused on medication and the patient's physical problems. But when one has mastered that part one can focus more on the patient's mental state." (R1)

\subsubsection{Being acknowledged by patients and relatives}

Working in palliative care entails becoming close with the patient and the relatives, which may become emotional for the nurse. The proximity with the patient's and relatives' feelings, the death, and the general situation further add to the nurse's emotional burden. The nurses experienced gratitude and positive response from, and emotional closeness with, relatives as confirmation of their professionalism. Such signs of appreciation make nurses feel happy and content in their work; some even see it as a gift.

"I'm very happy to be working in palliative care. Even though it can sometimes be very difficult to bear, I do love my work. It can be hard, but it also gives me a lot in return. It really does. One can do so much for both patients and relatives, so as to make the last time as good as possible for them. There aren't many jobs where one gets so much recognition as we do in many cases. In general, the patients are satisfied with the care we provide, which is very gratifying to know." (R6)

The nurses believed it is important to want to provide the best possible care in order to be acknowledged by the patient and relatives. To attain this goal, the nurses underlined the need of taking an interest in the patient, his or her needs and wishes, and those of any relatives involved, and of paying attention to the patient's dignity before and after the death.

"If one is truly interested in the patient everything can be taken care of during the journey; one always gets there somehow. If one really cares about the patient dying in a good way, solutions will be found. However, if you are not interested in the patient, then you cannot work with this kind of thing." (R2)

\subsubsection{Cooperating with colleagues and other profes- sional groups}

The nurses considered it important to be able to collaborate with colleagues and other professional groups. To work in teams was seen as strengthening when dealing with difficult situations and hard decisions. The nurses felt a need of receiving help from colleagues to handle the strain. Colleagues can provide comfort by saying that everything possible was done for the patient and that the right decisions were taken. Asking for help from more experienced colleagues is a way to achieve a sense of safety in one's professional role.

"One thing that has helped me a lot in this kind of nursing is the feeling of being one of the team; I think it's a fantastic team. Already from day one, I really felt the help and support provided by my colleagues." (R6)

Constant team work was seen as positive by the nurses, as it helps them adjust the care to the palliative-stage patient's needs and alleviate the strains on the staff. The possibility of creating good relationships between colleagues improves both the working atmosphere and the patient's palliative care. In the nurses' opinion, the opportunity to express thoughts and feelings to colleagues and other healthcare personnel provides a sense of safety.

“There are periods when you don't have the energy. You have to take a break. You must realize that you cannot have family after family. You must take a break. Then one has to tell a colleague: I see she is so sad and I cannot handle it." (R4)

\subsubsection{Separating work and private life}

The nurses believed that their private life is important for their ability to work with palliative-stage patients. The nurses saw a risk of taking work with them home, which can be emotionally trying and detrimental to private life and the quality of the care provide to palliative-stage patients. Nurses who are in the early stages of their career find it more difficult to disconnect from work during their private time.

"When one has just begun as a novice, one doesn't see when one is going too far, I think. One has to stop a little, not get into it too deeply, not forget there is a difference between oneself and the relatives." (R1)

Private life was seen as a resource and asset for the nurses. Having a hobby makes nurses feel better mentally, as they provide an occasion for nurses to air the difficult emotions encountered at work. The nurses also believed that it is important to separate work and private life, and to have a satisfying and relaxing leisure activity.

"I think that if you are going to do this kind of work, you should have something to do in your spare time, something that boosts your energy. I think it is hard to constantly be giving things to people, constantly emptying oneself, 
without getting anything back. This balance works well for me. It enables me to constantly recharge myself." (R6)

\subsection{Developing communication skills}

The nurses described communication as being a matter of continuously informing the patient and his or her relatives of the patient's state, symptoms, and medication. Problems, such as fear, anxiety and uncertainty about the future, can emerge among patients and relatives if the information is insufficient. The nurses observed that entering into dialog with the patient and relatives requires an ability and willingness to answer questions and speak about sensitive subjects, such as suffering and death.

\subsubsection{Talking with the patient}

The nurses believed that palliative-care communication skills require experience in talking with patients about, for instance, treatments and pathophysiology. The quality of the communication with the patient depends on how close the nurse has become with the patient and on the nature of the nurse-patient relationship. The nurses found that a wellinformed patient is aware of his or her symptoms, and their underlying reasons, and thereby becomes less anxious about the future. In the nurses' view, the most important information is that informing the patient of the decision to halt treatment and the decision's underlying rationale.

"If one is well-informed it works; it becomes much easier later when they become worse. If everyone agrees treatment should stop, that cessation is the right thing, then the right information has been given." (R1)

However, some nurses stressed that it is more important to listen to what the patient wants to talk about than to focus on medical matters. The nurses observed that some patients are not verbal and do not express a need of talking. At such occasions, it is important to pay attention to the unsaid, to pay attention to the patient's non-verbal expressions of pain, anxiety and fear.

Talking about death and the end of life can be emotionally exhausting for nurses. Such talks can provoke strong feelings of discomfort and anxiety for nurses. When feeling uncertain and fearful of speaking about death, nurses may even avoid the discussion with the patient entirely. The nurses stated that they are forced to maintain emotional distance to remain functional in their work. Sometimes this avoidance is due to the nurse's own fear of confronting death and existential anxiety.

"I feel it is very difficult to speak with them about the existential issues ... We need more knowledge and guidance about how to manage these talks when they are close to death and anxious ... Just starting to talk about such issues can be very difficult." (R4)

\subsubsection{Talking with the relatives}

Serious illness affects all family members. The nurses believed that it becomes easier to meet the patient's needs if they create a good relationship with the relatives. The nurses noted that relatives are often worried for the future. According to the nurses, relatives need the information early on in order to be able to be present throughout the course of the illness. Failing this, the relatives cannot understand the situation, and cooperation with them becomes difficult. The information should be repeated, as many times as needed, to increase the relatives' understanding and to give them a chance to come to terms with the situation.

"Sometimes we think the relatives know enough, but I think we give them too little information, especially medical information.” (R1)

\subsection{Having time for reflection}

The nurses believed that having time to think about and to discuss their feelings and experiences, in order to confirm their thinking and to cope, is an important part of their work. Different kinds of discussions are needed, such as coaching, discussions among the entire working group, and discussions with individual colleagues.

\subsubsection{Talking about one's feelings}

The nurses felt a need to talk about their feelings about difficult cases. The question of the handling of emotional stress was a central theme in the nurses' narratives. Caring for end-of-life patients is a complicated and extensive process, which often leads to emotional strains. Many of the nurses expressed a wish for higher quality in the care provided to dying patients. Whenever they feel they cannot provide the right care, they feel stressed and disappointed.

"You need to talk through the patient case in order to get over it. That's why you are emotionally finished, because you have nothing left to give." (R1)

The nurses felt that it is more difficult to take care of young palliative-stage patients than older patients. Younger patients are more emotionally draining and bring about feelings of fear for one's own health or that of one's family members. The nurses noted that when they become closer to some patients and relatives, they also become more emotionally touched. A nurse caring for an end-of-life patient 
experiences great frustration when she cannot help the patient. This frustration becomes worse when the nurse can identify with the patient, for instance if the nurse and the patient are close in age or there is a proximity in age between the nurse's children and the patient.

"I think it differs from patient to patient. It's a question of [the patient's] age ... a young patient or an 80-year-old patient. It depends on how close one has become to the patient and the relatives. One is more touched by the younger ones. It hurts more. One thinks of their relatives and small children. It is these patients one really needs to talk more about." (R4)

The nurses believed that the caring for end-of-life patients provokes emotional reactions, such as sadness, frustration, helplessness and inadequacy. Caring for patients who are about to die, and not being able to help them, causes frustration and emotional stress. Nurses are forced to confront their own existential anxiety and often think of the patients, leading to in particular mental stress.

"I chose to not take care of that patient, to say no in order to cope with the job and take care of other patients not in a palliative stage." (R1)

\subsubsection{Coaching}

The nurses believed that it is important to receive regular coaching by professionally trained staff. Coaching, in this setting, means having dedicated time to discuss, guided by professionals, difficult patient cases, so that nurses can learn from each other. Coaching also includes discussion about one's work situation and receiving acknowledgment from colleagues and management.

\subsection{Interpretation of the whole}

During the third and last phase of the analysis process all of the study's parts were gathered together and a new whole was created. This new whole, combined with the preunderstanding, uncovers the meaning hidden in the text. Thereby new meaning and deeper understanding of the phenomenon are gained. ${ }^{[32]}$

The interviewed nurses underlined the importance of growing in their role as a nurse, which requires increasing one's medical and professional knowledge and experience. Confidence as a nurse increases with experience. A new nurse may therefore find it difficult to handle the challenging situations that appear when caring for end-of-life patients. The new nurses stated that the medical part of palliative care is often a source of insecurity, for instance when issuing medication and handling technical equipment. The nurses noted that being present for the patient and relatives, and providing appropriate responses to their questions and emotions, is an important part of palliative caring, and that this requires professional maturity.

The nurses stated that they need continuous learning about human development, in particular psychology. It is also important to be able to read the patient's and relatives' needs, in order to be one step ahead in the illness process and be prepared for complications and changes in terms of needs. Acknowledgment from patients and relatives is very important for nurses, both as professionals and as human beings.

In order for the care for palliative-stage patients, and their relatives, to be a success, it is important to establish and maintain good communication. Good communication includes providing difficult information to both patient and relatives, and being able to discuss existential pain with them. The nurse can, by simply being present and available, invite the patient and the relatives to talk about their feelings about the illness and death.

The nurses also noted the importance of having good communications with colleagues. Talking with and getting support from colleagues is a source of strength that helps nurses cope with the strain of providing palliative care.

All the nurses stated that it is very important to have time to think about and discuss the experiences and feelings encountered when caring for end-of-life patients. The work pace is high and nurses feel there is no time for reflection. The nurses noted that they sometimes think about their patients and work during their leisure time. Nurses use different strategies to process their feelings, such as going for walks to think things over. The nurses stated that their work can have a negative impact on their private life, for instance by making them less social with their family. The nurses noted that it is very important to separate work and private life, in order to find the strength necessary for coping with the caring for palliative-stage patients.

\section{Discussion}

The results show that quality palliative care requires medical-technical knowledge, medical knowledge, experience of palliative caring and professional and personal selfconfidence when caring for dying patients. When meeting a dying patient and his or her relatives, the nurse faces a major emotional challenge, which may be overpowering if the nurse does not feel mature in her professional role. According to Eriksson, ${ }^{[24,25]}$ the nurse's ability to face and alleviate the patient's suffering depends on the nurse's own maturity. Eriksson observes that one of the nurse's most important tasks is to alleviate the patient's suffering and to provide comfort. An earlier study confirms that nurses meeting suffering and death in their daily work are forced to deal with existential questions about life and death. ${ }^{[36]}$ 
Newly graduated nurses can experience the caring for dying patients and their relatives as very trying. The demands nurses make on themselves can affect their self-esteem as a person and as a nurse. If new nurses compare themselves to more experienced nurses, they may feel disappointed with themselves and become insecure in their professional role.

Daring to be present can be interpreted as the nurse using all her senses and inner resources to alleviate the patient's and relatives' suffering. In order for the nurse's palliative-care knowledge and skills to develop, she must take the time to see the whole patient and his or her situation. This means that the nurse must have, in addition to medical knowledge, self-knowledge and an inner desire to provide good palliative care. According to the interviewed nurses in this study, the core issue when providing palliative care is the ability to see the patient's and relatives' needs as a greater whole.

The nurses underlined the importance for them of the positive acknowledgment received from patients and relatives. All the nurses stressed that they liked their work very much and that they would not want to work with anything else. The nurses were content with their work, despite the fact that it is trying to meet dying patients every day. According to Friedrichsen, ${ }^{[37]}$ palliative-care nurses have certain characteristic traits: they are outgoing, self-confident, perceptive and group-oriented. Nurses working with end-of-life patients also need, besides their medical knowledge, knowledge about life issues and existential philosophy. An earlier study confirms that the meeting with the dying patient forces the nurse to deal with existential questions about the meaning of life. ${ }^{[38]}$

The interviewed nurses stressed the value of developing one's communication skills in relation to the patient and relatives. According to Karlsson and Sandén, ${ }^{[39]}$ good palliative caring demands successful communication and a good relationship with the patient and relatives. Good communication comprises, in Twycross's view, ${ }^{[40]}$ being capable of providing information that the patient can understand and of developing relationships. The creation of good communication requires good self-insight and awareness of one's own failings. This reasoning is in line with Reitan's claim ${ }^{[41]}$ that nurses must have the will and courage to take an active interest in the patient's needs and problems. The nurse must be capable of facing her own fear and aversion to difficult talks. The nurse's fear of not being able to handle the emotional talk can lead her to not talk at all.

Suffering consumes a person's dignity ${ }^{[24,25]}$ and often this leads to the person not talking about his or her suffering and needs. For the sake of providing the best possible care, it is therefore important the nurse interprets the patient's and relatives' various signals correctly. An earlier study describes how important it is that the nurse understands the patient's experience of the loss of body control, and that the nurse can interpret the patient's needs. ${ }^{[36]}$
This study shows that nurses need personal maturity and life- and work experience, in order to dare enter into discussion with the patient about his or her fear of, and questions about, suffering and death. The nurse's own fear and feelings about death can make her avoid difficult discussions with the patient. In particular newly graduated nurses, with little or no experience of dealing with palliative-stage patients, can experience feelings of loneliness and inadequacy in the meeting with patients and relatives. Such feelings among nurses have been observed in earlier studies and have been linked to their lacking ability to communicate with patients and relatives ${ }^{[2]}$ and their insufficient training in among other things communication. ${ }^{[42]}$ The talk with the patient is often emotionally charged and difficult for the nurse to handle. ${ }^{[3]}$ This is why the nurses in this study, in particular those with little work experience, expressed feelings of frustration, inadequacy and failure in their role as nurses. The struggle to provide quality care to patients and relatives can be hard when the nurse cannot live up to the expected ideal.

The daily meeting with suffering and death can lead to feelings of emotional emptiness among nurses. In a study by Sandgren, ${ }^{[44]}$ it emerged that nurses can feel emotionally overburdened when they lack social competence and support from colleagues. Meeting suffering patients and relatives is emotionally and psychologically draining for nurses. It is important to be able to seek support from colleagues with longer work experience. The opportunity to talk about one's feelings strengthens the nurses' ability to continue with their work. Nurses also need support from managers and other professional groups, including physicians, in order to be able to handle difficult situations with palliativestage patients and their relatives.

According to Eriksson, ${ }^{[24,25]}$ religious belief can be a source of courage and strength for nurses dealing with palliativestage patients and their suffering and death.

The nurses in the study underlined the importance of separating work and private life. In order to cope with the work and feel emotionally well, nurses need a functioning private life. The nurses noted that leisure activities are a way to distance oneself from work and to regain energy. Karlsson-Källström ${ }^{[36]}$ speaks about the nurses' need to distance themselves from death by socializing with family and friends, having leisure activities, and being outdoors. Separation between work and private life is the foundation of the nurses' well-being and emotional balance. Separation safeguards nurses from being emotionally drained by their workplace experiences.

The results of earlier research on palliative care ${ }^{[2,45]}$ has underlined the great psychological strain experienced by nurses. To develop palliative care, further studies are needed about palliative care nurses' work situation. Nurses need more support and coaching in order to handle their feelings and experiences and to develop as professionals. According 
to a Swedish government official report, ${ }^{[3]}$ palliative care should be a priority issue. It is therefore important to study palliative care from the nurses' perspective, as there is a clear link between the well-being of palliative care nurses and the quality of the care provided to palliative-stage patients.

This study has made three main contributions to the field: 1) The finding that caring for palliative-stage patients requires medical-technical knowledge, medical knowledge, experience of palliative caring, and professional and personal self-confidence. 2) The finding that nurses need regular coaching by staff and professionals with more experience dealing with and processing suffering, death and related existential issues. 3) The finding that nurses need to separate work from private life and have satisfying and relaxing leisure activities. These three factors are necessary for nurses to achieve well-being in their work and provide quality care to palliative-stage patients and their relatives.

\subsection{Study limitations}

Phenomenological-hermeneutic method was used for the data collection to study nurses' experiences of caring for palliative-stage patients. Lindseth and Norberg ${ }^{[32]}$ state that the interviewer should encourage the respondent to talk as freely as possible about the subject matter, and ask openended follow-up questions to increase the preunderstanding of the respondent's narrative.

To strengthen the study's validity, the researchers have provided quotations from the interview texts. ${ }^{[34]}$ To strengthen the study's reliability, the researchers have carefully described how the interviews were carried out, and how the data collected was transcribed, processed and analyzed. The research group has continuously discussed the study and strived to maintain as open-minded an attitude as possible. Throughout the research process the hermeneutic spiral has been used ${ }^{[46]}$ to shift between the text's whole and its parts.

Strategic selection ${ }^{[34]}$ was used with the hope that the data would provide a wide range of nurse experiences of caring for palliative patients. The respondents were of different ages and had different lengths of work experience in palliative care. Strategic selection could be seen as possible coercion. However, the researchers repeatedly underlined the voluntary nature of participation, and reminded the respondents that they could discontinue participation at any time.

In phenomenological-hermeneutic method the text is analyzed using preunderstanding and interpretation of the text. The researchers' preunderstanding can be a resource strengthening the understanding of the respondents' experiences; conversely, it can be a hindrance if it influences and restricts the researcher's open-mindedness. The researchers have tried to be as open-minded as possible during the naive reading of the text. To reduce the possibility of bias, the researchers carefully kept in mind the fact that they, due to their participation in the qualitative interview setting, may have an impact on the interview's content. ${ }^{[34]}$

The purpose of phenomenological-hermeneutic analysis being to highlight the individual's experience, not to generalize, the researchers limited the study population to six nurses. As the purpose was to analyze the phenomenon qualitatively, not to quantify it or be representative of the study population, strategic selection was considered appropriate. ${ }^{[32,34]}$ The fact that the study population comprised only women may be seen as a limitation.

\subsection{Practical implications and further research}

The study's results show that nurses feel that time should regularly be set aside for reflection and coaching. They feel that discussion about their experiences and thoughts with colleagues and other professional groups involved in palliative care provides opportunities for learning together and from each other, and for increased professionalism in the meeting with the palliative-care patient and relatives. Coaching is needed so that nurses can speak about their palliative-care work situation and receive help to process their emotions. Team work provides a sense of safety when handling difficult situations and taking difficult decisions. This study can provide guidance and help for understanding the needs of palliative-care nurses and other staff in similar positions in the healthcare organization. The findings can be of benefit both to palliative care nurses, individually or acting as a group, and to healthcare organization managers.

\section{Conclusion}

The importance of having a holistic perspective, encompassing understanding of both the patient's and the relatives' needs, emerges as the core of palliative care. To be able to provide care for palliative-stage patients nurses need professional experience, self-confidence in their role as a nurse, medical knowledge, self-insight, and personal maturity. In order to handle the heavy emotional strain caused by their work with palliative-stage patients, nurses need support from colleagues and hospital management. Palliative-care nurses need dedicated time for reflection and coaching to handle their feelings and difficult meetings with palliative-stage patients. Being able to separate work and private life strengthens the nurse's ability to provide quality palliative care.

\section{Acknowledgements}

The authors thank Patrick Reis for his writing, translation and proofreading assistance for this article. The authors also thank the respondents for sharing their experiences.

\section{Conflicts of Interest Disclosure}

The authors declare that they have no conflict of interest. 


\section{References}

[1] World Health Organization. Palliative care. Geneva. World Health Organization. 2011.

[2] Sandgren A, Thulesius H, Fridlund B, et al. Striving for emotional survival in palliative cancer nursing. Qualitative Health Research. 2006 January; 16(1): 79-96. http://dx.doi.org/10.1177/104 9732305283930

[3] SOU. Death affects us all - worthy of terminal care. Final report of the Committee on end of life care. Government Official Reports. Stockholm: Ministry of Health. 2001: 6.

[4] Isaksen AS, Thuen F, Hanestad B. Patients with cancer and their close relatives: experiences with treatment, care, and support. Cancer Nursing. 2003 February; 26(1): 68-74. PMid:12556715. http: //dx.doi.org/10.1097/00002820-200302000-00010

[5] Johansson CM, Axelsson B, Danielson E. Living with incurable cancer at the end of life - patients' perceptions on quality of life. Cancer Nursing. 2006 September-October; 29(5): 391399. PMid:17006113. http://dx.doi.org/10.1097/0000282 0-200609000-00007

[6] Kvale K. Do cancer patients always want to talk about difficult emotions? A qualitative study of cancer inpatients communication needs. European Journal of Oncology Nursing. 2007; 11(4): 320327. http://dx.doi.org/10.1016/j.ejon.2007.01.002

[7] Berterö C, Vanhanen M, Appelin G. Receiving a diagnosis of inoperable lung cancer: patients' perspectives of how it affects their life situation and quality of life. Acta Oncologica. 2008; 47(5): 862-9. http://dx.doi.org/10.1080/02841860701654333

[8] Sand L, Strang P, Milberg A. Dying cancer patients' experiences of powerlessness and helplessness. Support Care Cancer. 2008 July; 16(7): 853-862. PMid:18026998. http://dx.doi.org/10.1007 /s00520-007-0359-z

[9] Berterö C. Caring for and about cancer patients: identifying the meaning of the phenomenon "caring" through narratives. Cancer Nursing. 1999 December; 22(6): 414-420. PMid:10603688.

[10] Cohen MZ, Sarter B. Love and work: oncology nurses' view of the meaning of their work. Oncology Nursing Forum. 1992 NovemberDecember; 19(10): 1481-1486. PMid:1461762.

[11] Artinian BM. Risking involvement with cancer patients. Western Journal of Nursing Research. 1995; 17(3): 292-304. PMid:7778311. http://dx.doi.org/10.1177/019394599501700305

[12] Widmark-Petersson V, von Essen L, Sjödén PO. Perceptions of caring among patients with cancer and their staff. Differences and disagreements. Cancer Nursing. 2000 February; 23(1): 32-39. PMid:10673805. http://dx.doi.org/10.1097/00002 820-200002000-00005

[13] Escot C, Artero S, Gandubert C, et al. Stress levels in nursing staff working in oncology. Stress \& Health. 2001 September; 17(5): 273279. http://dx.doi.org/10.1002/smi. 907

[14] Block SD. Perspectives on care at the close of life. Psychological considerations, growth, and transcendence at the end of life: the art of the possible. The Journal of the American Medical Association. 2001 June; 285(22): 2898-2905. http://dx.doi.org/10.1001 /jama.285.22.2898

[15] Grbich C, Parish K, Glaetzer K, et al. Communication and decision making for patients with end stage diseases in an acute care setting. Contemporary Nurse. 2006 October; 23(1): 21-37. http: //dx.doi.org/10.5172/conu.2006.23.1.21

[16] Wallerstedt B, Andershed B. Caring for dying patients outside special palliative care settings: experiences from a nursing perspective. Scandinavian Journal of Caring Sciences. 2007 April; 21(1): 32-40.

[17] Radziewicz RM. Self-care for the caregiver. Nursing Clinics of North America. 2001; 36(4): 855-69. PMid:11726358.

[18] Sivesind D, Parker P, Cohen L, et al. Communicating with patients in cancer care; What areas do nurses find most challenging? Journal of Cancer Education. 2003 Winter; 18: 202-209. PMid:14766330. http://dx.doi.org/10.1207/s15430154jce1804_7
[19] Uitterhoeve R, de Leeuw J, Bensing J, et al. Cue-responding behaviour of oncology nurses in video-simulated interviews. Journal of Advanced Nursing. 2007 November; 61(1): 71-80.

[20] Kruijver IPM, Kerkstra A, Bensing JM, et al. Communication skills of nurses during interactions with simulated cancer patients. Journal of Advanced Nursing. 2001 December; 34(6): 772779. PMid:11422547. http://dx.doi.org/10.1046/j.1365-2 $648.2001 .01807 . x$

[21] Quinn B. Exploring nurses' experiences of supporting a cancer patient in their search for meaning. European Journal of Oncology Nursing. 2003 September; 7(3): 164-171. http://dx. doi .org/1 $0.1016 / \mathrm{S} 1462-3889(03) 00019-\mathrm{X}$

[22] Swedish Society of Nursing. Competence Description for Registered Nurse with specialist nursing oncology care. Stockholm: Swedish Society of Nursing; 2008a.

[23] Swedish Society of Nursing. Competence Description for Registered Nurse with specialist nursing district nurse. 2008b.

[24] Eriksson K. To alleviate suffering. In K. Eriksson, A. Barbosa da Silva (ed.), Care Theology. Turku: Åbo Akademi University Copy Centre; 1991.

[25] Eriksson K. The suffering person. Arlöv: Oxford; 1994.

[26] Valand E, Fodstad G. Generell onkologisk omvårdnad. In: H. Almås (Eds.), Klinisk omvårdnad del 1. Stockholm: Liber; 2006.

[27] Tsai JS, Wu CH, Chiu TY, et al. Symptom patterns of advanced cancer patients in a palliative care unit. Palliative Medicine, 2006 September; 20(6): 617-622. PMid:17060255. http://dx.doi.o $\mathrm{rg} / 10.1177 / 0269216306071065$

[28] National Board. National Board assessment of developments in counties and municipalities. Stockholm: National Board of Health; 2006.

[29] National Board. Research that reflects palliative care: a compilation of current research. Stockholm: National Board of Health; 2007.

[30] Grande G. Palliative care in hospice and hospital: time to put the spotlight on neglected areas of research. Palliative Medicine. 2009 April; 23(3): 187-189. http://dx.doi.org/10.1177/0269216 309102697

[31] Addington-Hall JM, O'Callaghan AC. A comparison of the quality of care provided to cancer patients in the UK in the last three months of life in in-patient hospices compared with hospitals, from the perspective of bereaved relatives: results from a survey using the VOICES questionnaire. Palliative Medicine. 2009; 23(3): 190-197. http://dx.doi.org/10.1177/0269216309102525

[32] Lindseth A, Norberg A. A phenomenological hermeneutical method for researching lived experience. Scandinavian Journal of Caring Sciences. 2004 May; 18(2): 145-153. http://dx.doi.org/10. $1111 / j .1471-6712.2004 .00258 . x$

[33] Ricoeur P. Hermeneutics and human sciences. Cambridge MA, Cambridge: University Press; 1981.

[34] Trost J. Kvalitativa intervjuer. Lund: Studentlitteratur; 2010.

[35] Research Council. Research ethical principles in the humanities and social sciences. Stockholm: Elanders Gotab; 2002. Available from: http://www. codex.vr.se/texts/HSFR.pdf

[36] Källström-Karlsson I. To live close to death. Patients and professionals experience in hospice care. Orebro University: Department of Nursing; 2009

[37] Friedrichsen M. The nurse in palliative care - a role of adjustment and balance. IN: B. Beck Friis, Strang P. (Eds.), Palliative medicine. Stockholm: Liber; 2005.

[38] Karlsson M, Roxbergh A, Barbosa da Silva A, et al. Community nurses 'experiences of ethical dilemmas in palliative care: a Swedish study. International Journal of Palliative Nursing. 2010 May; 16(5): 224-231. http://dx.doi.org/10.12968/ijpn.2 010.16 .5 .48143

[39] Karlsson M, Sandén I. A group of nurses' descriptions of good care situations in palliative care. Care in the Nordic region. 2007; 83 (27): 50-53.

[40] Twycross R. Palliative care. Lund: Studentlitteratur; 1998.

[41] Reitan M. Kommunikation. In: T. Schölberg, AM Reitan (Eds.), Oncology Nursing. Patient trouble-measure. Communication. Stockholm: Liber; 2003. 
[42] Georgaki S, Kalaidopoulou O, Liarmakopoulos I, et al. Nurses' attitudes toward truthful communication with patient with cancer - a Greek study. Cancer Nursing. 2002 December; 25(6): 436441. PMid:12464835. http://dx.doi.org/10.1097/0000282 0-200212000-00006

[43] Kennedy Sheldon L, Barret R, Ellington L. Difficult Communication in Nursing. Journal of Nursing Scholarship. 2006 May, 38(2): 141-147. http://dx.doi.org/10.1111/j.1547-5069. $2006.00091 . x$
[44] Sandgren A. Deciphering unwritten rules. Linnaeus Universitet, Institution for Nursing: Växjö; 2010.

[45] McCloskey S, Taggart L. How much compassion have I left? An exploration of occupational stress among children's palliative care nurses. International Journal of Palliative Nursing. 2010; 16(5): 233240. http://dx.doi.org/10.12968/ijpn.2010.16.5.48144

[46] Hallberg M. Hermeneutik. In: C. Allwood, M. Erikson (Eds.), Theory of psychology and other social sciences. Lund: Studentlitteratur; 1999. 